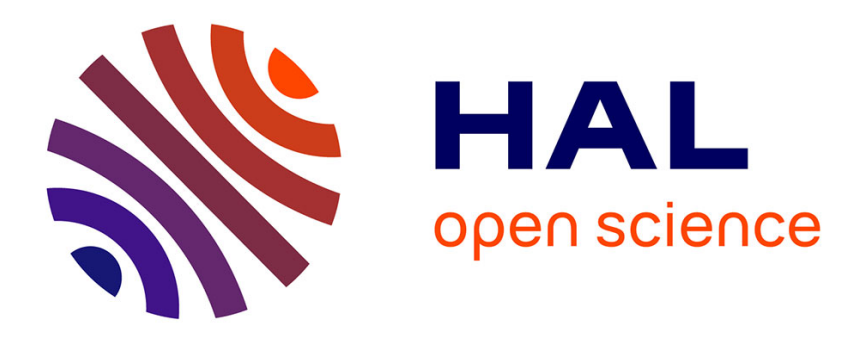

\title{
Unpolarized infrared emissivity of oil films on sea surfaces
}

\author{
Nicolas Pinel, Christophe Bourlier
}

\section{To cite this version:}

Nicolas Pinel, Christophe Bourlier. Unpolarized infrared emissivity of oil films on sea surfaces. International Geoscience and Remote Sensing Symposium, Jul 2009, Le Cap (Cape Town), South Africa. pp.1258. hal-00426432

\section{HAL Id: hal-00426432 \\ https://hal.science/hal-00426432}

Submitted on 26 Oct 2009

HAL is a multi-disciplinary open access archive for the deposit and dissemination of scientific research documents, whether they are published or not. The documents may come from teaching and research institutions in France or abroad, or from public or private research centers.
L'archive ouverte pluridisciplinaire HAL, est destinée au dépôt et à la diffusion de documents scientifiques de niveau recherche, publiés ou non, émanant des établissements d'enseignement et de recherche français ou étrangers, des laboratoires publics ou privés. 


\title{
UNPOLARIZED INFRARED EMISSIVITY OF OIL FILMS ON SEA SURFACES
}

\author{
Nicolas Pinel and Christophe Bourlier
}

\author{
IREENA Laboratory, Université de Nantes \\ Polytech'Nantes, La Chantrerie, Rue Christian Pauc, BP 50609, 44306 NANTES Cedex 3, FRANCE
}

\begin{abstract}
The unpolarized infrared emissivity of oil films on sea surfaces is derived under the geometric optics approximation. The multiple reflections at each of interface are ignored, but the multiple reflections between the upper and lower interfaces of the oil film are taken into account. The oil film is assumed to be thin, so that the two interfaces can be considered as parallel and identical. Thus, under the geometric optics approximation, the oil film can locally be seen as a Fabry-Pérot interferometer. Thus, the emissivity of the contaminated sea can easily be obtained from the emissivity of the air/oil interface only. Emissivity comparisons between clean and contaminated seas are then presented to study the oil film detectability.
\end{abstract}

Index Terms - Sea surface, Water pollution, Infrared detectors, Optical propagation, Geometrical optics.

\section{INTRODUCTION}

Remote sensing, by either radar or optical imagery, can be used to detect and monitor possible oil slicks on sea surfaces $[1,2]$. For optical applications, in order to act quickly when marine oil pollutions occur, it is then essential to dispose of a means that can predict the emissivity, which quantifies the intrinsic radiation of the surface. Then, by calculating the contrast between a sea covered by an oil film (called contaminated sea) and a clean sea, it is possible to study the detectability of marine pollutions.

For optical or infrared (IR) applications, at moderate angles, since the electromagnetic wavelength $\lambda$ is much smaller than the sea surface mean curvature radius $R_{c}$, the tangent plane approximation (usually called Kirchhoff approximation, KA) can be applied. Moreover, the electromagnetic wavelength $\lambda$ being also much smaller than the surface root mean square (RMS) height $\sigma_{h}$ for both clean and contaminated seas, the geometric optics approximation (GOA) can be applied. Indeed, at optical or IR frequencies, the capillary waves of sea surfaces also have a large mean curvature radius and a large RMS height comparatively to the wavelength $\lambda$.

From an analytical approach based on previous work [3], the unpolarized emissivity of a thin oil film over a $2 \mathrm{D}$ anisotropic rough sea surface (i.e., for a general 3D problem) is derived under the GOA. Attention is focused here on the case of homogeneous insoluble oil films, which restricts the validity domain of the study to low to moderate wind speeds at 10 meters above the sea surface $u_{10}$ less than $8-10 \mathrm{~m} / \mathrm{s}$ $[4,5]$. The multiple reflections at each interface are ignored (i.e., for both the upper air/oil interface and the lower oil/sea interface for the contaminated case). By contrast, the multiple reflections between the upper and the lower interfaces of the oil film are taken into account by assuming a locally flat and planar thin oil film. In other words, the two surfaces of the oil film are assumed to be strictly identical and parallel, so that the film can be locally seen as a Fabry-Pérot interferometer. This implies that the whole oil film problem can be treated from the single air/oil surface problem, by substituting the Fresnel reflection coefficient of air/oil single interface for the equivalent Fresnel reflection coefficient of the air/oil/sea film. The calculations are led for IR wavelengths, inside the two windows regions $3-5 \mu \mathrm{m}$ and $8-13 \mu \mathrm{m}$ at the wavelengths $3.4 \mu \mathrm{m}$ and $10 \mu \mathrm{m}$, for which the refractive indexes of the sea water (taken from the refractive index of pure water by Hale and Querry [6] with the salinity adjustment from Friedman [7]) and the oil $[8,9]$ are given in Table 1 . Since under the GOA, the emissivity depends on the slope PDF (Probability Density Function), the RMS slope along the wind direction of a contaminated sea surface must be calculated. In this paper, one model of surface slope damping due to oil films is studied: the Lombardini et al. damping model [10], is a rather simple model which is independent of the oil film thickness.

In what follows, in section 2, the hydrodynamic modeling of the surfaces of clean and contaminated seas is described. In section 3 , the emissivity contrast between a clean sea and a contaminated sea is calculated, and the oil film detectability is studied.

\section{HYDRODYNAMIC MODELING OF THE SURFACES OF CLEAN AND CONTAMINATED SEAS}

The hydrodynamic modeling of the surfaces of clean and contaminated seas is based on the Elfouhaily et al. model [11] for the case of a clean sea. By comparison, for the case of a contaminated sea, a damping effect occurs, which has a maximum located in the gravity-capillarity region of the surface wave spectrum, around the surface wave frequency $\nu_{s}=10$ 


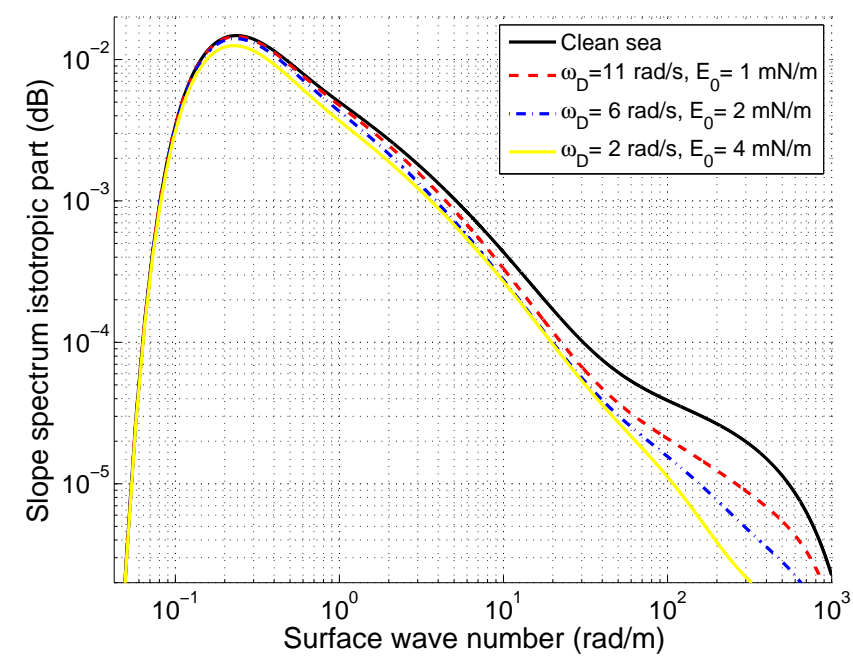

Fig. 1. Isotropic part of the surface slope spectrum of clean and contaminated seas (using the Lombardini et al. damping model) versus the surface wavenumber $k_{s}$. The wind speed is $u_{10}=7 \mathrm{~m} / \mathrm{s}$.

Hz. This damping effect is expressed by an attenuation coefficient $y$ [10], which is usually called the Marangoni viscous damping coefficient. For more details, one can refer to [4].

To describe this damping effect, we refer to two distinct hydrodynamic models of the literature. The first one, namely the Lombardini et al. damping model [10], is rather simple, as it depends on only 2 hydrodynamic parameters, but in return is independent of the film thickness $H$. The second one, namely the Jenkins and Jacobs damping model [12], is more sophisticated, as it depends on 9 hydrodynamic parameters and depends on the film thickness $H$, but is valid only for thin films. Here, we concentrate on the first model, and represent in Fig. 1 the surface slope spectrum of clean and contaminated seas for a wind speed at 10 meters above the sea surface $u_{10}=7 \mathrm{~m} / \mathrm{s}$, with different values of the two parameters $\omega_{D}$ and $E_{0}$ of the Lombardini et al. model $\left(\omega_{D}\right.$ being the oil characteristic pulsation, and $E_{0}$ the oil elasticity modulus). These two parameters are chosen to match experimental results of both the surrface wind wave spectrum damping [13,14] and the RMS slope [15]. As expected, one can observe in Fig. 1 that the oil film strongly damps the high frequencies corresponding to the capillary waves. Comparatively to higher values of $E_{0}$, which typically correspond to organic films, the damping in the high frequencies is in general weaker for oil films than for organic films. Moreover, the damping is stronger for $\omega_{D}=1 \mathrm{rad} / \mathrm{s}, E_{0}=4 \mathrm{mN} / \mathrm{m}$ than for $\omega_{D}=10 \mathrm{rad} / \mathrm{s}, E_{0}=2 \mathrm{mN} / \mathrm{m}$, which is stronger than for $\omega_{D}=16 \mathrm{rad} / \mathrm{s}, E_{0}=1 \mathrm{mN} / \mathrm{m}$.

Then, this hydrodynamic modeling is applied in section 3 to the infrared emissivity of clean and contaminated seas, in order to study the detectability of oil films. To do so, it must be noted that both the upper (air-oil) and lower (oil-sea) interfaces of the oil film obey the same hydrodynamic modeling, with identical parameters. Moreover, as dealing with thin oil films, it is assumed that the two interfaces of the oil film are strictly identical and parallel (see Fig. 5 of [4]). In what follows, the surface slope spectrum is used to calculate the surface RMS slopes, in the up-wind direction $\sigma_{s x}$ and in the cross-wind direction $\sigma_{s y}$, for both clean and contaminated seas. Indeed, $\sigma_{s x}$ and $\sigma_{s y}$ are parameters of the slope probability density function which appears in the expression of the infrared emissivity under the GOA [3].

\section{INFRARED EMISSIVITY OF CLEAN AND CONTAMINATED SEAS}

Under the GOA, which is based on the KA, the two interfaces of the oil film can be considered as locally flat and parallel. Consequently, for moderate emission angles and for thin films, the oil film can be considered as locally flat, and appears as a local Pérot-Fabry interferometer. Then, the multiple reflections between the upper and the lower interfaces of the oil film can be modeled in a simple way. Indeed, starting from the single (air/oil) interface case, under the GOA, the Fresnel reflection coefficient of a single interface can be substituted for the equivalent Fresnel reflection coefficient of the air/oil/sea film, calculated by considering an infinite number of reflections inside the film. Its expression is given by equation (9) of [4].

In this paper, from an analytical approach based on the work of Bourlier [3], the unpolarized emissivity from a thin oil film over a two-dimensional anisotropic sea surface is derived by using the GOA.

Then, the infrared emissivities of clean and contaminated seas can be computed. Fig. 2 represents the unpolarized infrared emissivities of clean and contaminated seas with respect to the emission angle $\theta$, for a wavelength $\lambda=3.4 \mu \mathrm{m}$, a wind speed $u_{10}=7 \mathrm{~m} / \mathrm{s}$, and a wind direction $\phi=0$. The contaminated sea is a heavy oil film of thicknesses $H=\{0 ; 10 ; 50 ; 100\} \mu \mathrm{m}$, described by the Lombardini et al. damping model with parameters $\omega_{D}=11 \mathrm{rad} / \mathrm{s}$ and $E_{0}=1 \mathrm{mN} / \mathrm{m}$. The case $H=0$ is plotted to highlight the influence of the surface wave damping due to the presence of oil. The result of the contaminated sea for zero thickness $H=0$ is very close to the one of the clean sea. Indeed, differences appear only for relatively high emission angles $\theta$, owing to the damping of the capillarity waves in the surface wave slope spectrum due to the presence of oil. Then, for these typical wind speeds, the damping due to the presence of oil has an effect on the unpolarized emissivity only for high emission angles $\theta$. Similarly, the results with various thicknesses do not highlight significant differences with the clean sea case, except for high $\theta$. In fact, the various thicknesses represented here highlight a small and seemingly constant (negative) difference with zero thickness $H=0$. Thus, the 


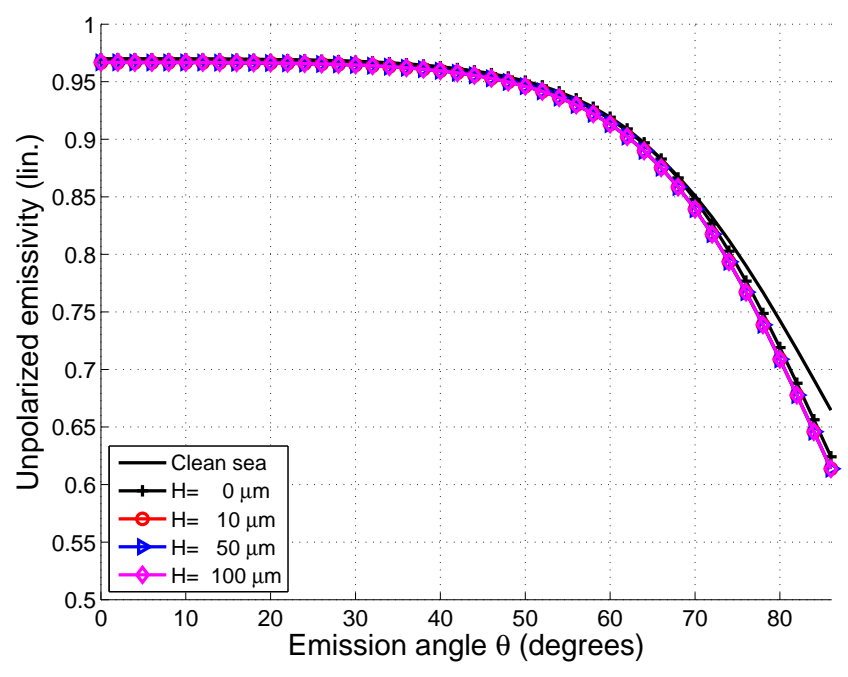

Fig. 2. Unpolarized emissivities of clean and contaminated seas versus the emission angle $\theta$, for $\lambda=3.4 \mu \mathrm{m}, u_{10}=7$ $\mathrm{m} / \mathrm{s}$, and $\phi=0$. The contaminated sea is a heavy oil film of thicknesses $H=\{0 ; 10 ; 50 ; 100\} \mu \mathrm{m}$, described by the Lombardini et al. damping model with parameters $\omega_{D}=11$ $\mathrm{rad} / \mathrm{s}$ and $E_{0}=1 \mathrm{mN} / \mathrm{m}$.

oil film detection is possible here only for high emission angles $\theta$. Moreover, the differences between the various thicknesses being negligible, the oil film thickness estimation is impossible at this wavelength.

Fig. 3 presents the same simulations as in Fig. 2, but for a wavelength $\lambda=10 \mu \mathrm{m}$. For zero thickness $H=0$, the same observations can be done: differences with the clean sea case are observable only for high $\theta$. This highlights the influence of the capillary wave surface damping onto the emissivity. Indeed, it is well-known that the capillary waves play an increasing role as the observation angle $\theta$ increases. Contrary to Fig. 2 where $\lambda=3.4 \mu \mathrm{m}$, here for $\lambda=10 \mu \mathrm{m}$ the results with various thicknesses highlight differences with the case $H=0$ and, most important, with the clean sea case. The differences being significant, this makes the oil film detectable. Moreover, depending on the emission angle $\theta$, it can be seen that the results with various thicknesses highlight significant differences between theses thicknesses, and a general different behavior with respect to $\theta$. Then, from the knowledge of the emissivity of an oil film for a few values of $\theta$, this makes it possible to estimate the oil film thickness.

Fig. 4 represents the unpolarized infrared emissivities of a contaminated sea for two wavelengths $\lambda=3.4 \mu \mathrm{m}$ and for either a heavy or a light oil film of thickness $H=50 \mu \mathrm{m}$, the other parameters being the same as previously. For the lower wavelength $\lambda=3.4 \mu \mathrm{m}$, the differences between a heavy and a light oil is not significant, making the oil characterization impossible. By contrast, for $\lambda=10 \mu \mathrm{m}$, differences between the two oil types appear for either low or high observation an-

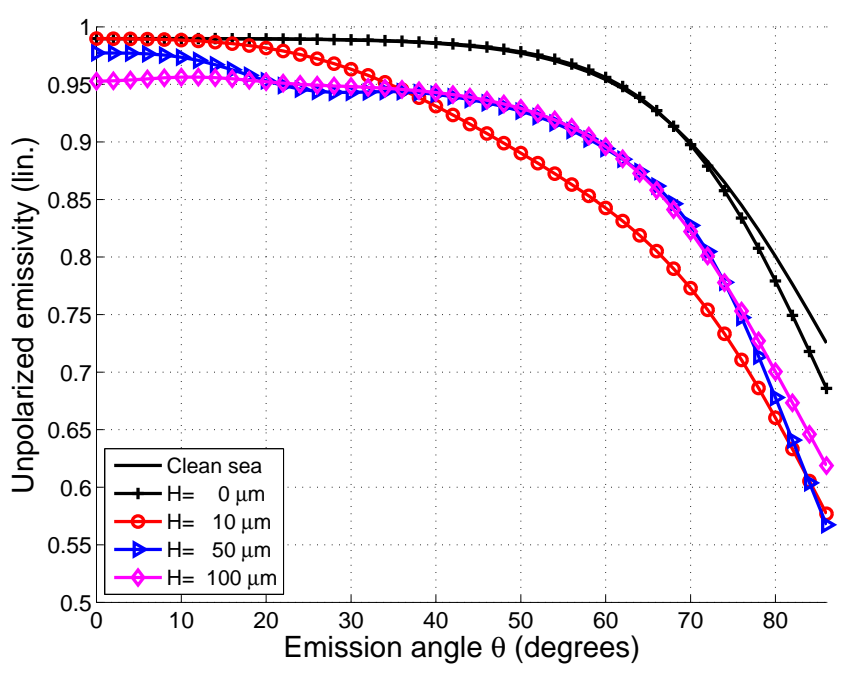

Fig. 3. Same simulations as in Fig. 2, but for a wavelength $\lambda=10 \mu \mathrm{m}$

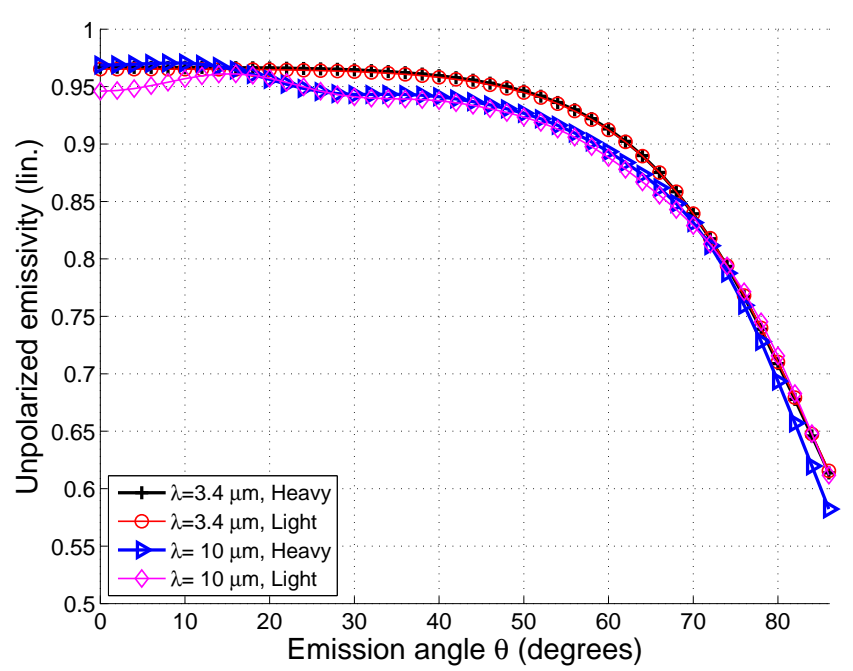

Fig. 4. Unpolarized emissivities of a contaminated sea versus the emission angle $\theta$, for $\lambda=\{3.4,10\} \mu \mathrm{m}, u_{10}=7 \mathrm{~m} / \mathrm{s}$, and $\phi=0$. The contaminated sea is either a heavy or a light oil film of thickness $H=50 \mu \mathrm{m}$, described by the Lombardini et al. damping model with parameters $\omega_{D}=11 \mathrm{rad} / \mathrm{s}$ and $E_{0}=1 \mathrm{mN} / \mathrm{m}$. 
Table 1. Refractive indexes of the sea water (taken from the refractive index of pure water by Hale and Querry [6] with the salinity adjustment from Friedman [7]), and the oil [8, 9] for $\lambda=\{3.4 ; 10\} \mu \mathrm{m}$, respectively.

\begin{tabular}{c|c|c}
\hline Sea water & Heavy petroleum & Light petroleum \\
\hline $1.426+j 0.019$ & $1.41+j 0.160$ & $1.45+j 0.080$ \\
\hline $1.227+j 0.050$ & $1.52+j 0.002$ & $1.53+j 0.001$
\end{tabular}

gles $\theta$. Thus, this highlights the possibility of characterizing different oil types at this typical wavelength, which can be useful to determine the origin of an oil pollution.

\section{CONCLUSION AND FUTURE WORK}

In conclusion, the emissivity of clean and contaminated seas was computed by using the classical geometric optics approximation for one interface. The extension to the contaminated sea was done by using the Lombardini et al. damping model with parameters chosen to get good agreement with experimental results $[13,14,15]$, and by considering an oil film with two identical and parallel interfaces. Numerical results are then presented in the middle of the infrared window regions, at $\lambda=3.4 \mu \mathrm{m}$ and at $\lambda=10 \mu \mathrm{m}$. Thus, at the lower wavelength $\lambda=3.4 \mu \mathrm{m}$, the oil film detection is possible mainly for high observation angles $\theta$, and the oil film characterization and thickness estimation are impossible. By contrast, at the higher wavelength $\lambda=10 \mu \mathrm{m}$, the oil film is much easier and it is possible in general at any observation angle $\theta$. Moreover, the oil film characterization is possible for either low or high $\theta$, and the thickness estimation is hoped-for if measurements are made at several observation angles $\theta$.

\section{REFERENCES}

[1] V. Wismann, M. Gade, W. Alpers, and H. Hühnerfuss, "Radar signature of marine mineral oil spills measured by an airborne multi-radar," International Journal of Remote Sensing, vol. 19, no. 18, pp. 3607-23, Dec. 1998.

[2] H. A. Espedal and O. M. Johannessen, "Detection of oil spills near offshore installations using synthetic aperture radar (SAR)," International Journal of Remote Sensing, vol. 21, no. 11, pp. 2141-2144, July 2000.

[3] C. Bourlier, "Unpolarized infrared emissivity with shadow from anisotropic rough sea surfaces with nonGaussian statistics," Applied Optics, vol. 44, no. 20, pp. 4335-49, July 2005.

[4] N. Pinel, N. Déchamps, and C. Bourlier, "Modeling of the bistatic electromagnetic scattering from sea surfaces covered in oil for microwave applications," IEEE Transactions on Geoscience and Remote Sensing, vol. 46, no. 2, pp. 385-392, Feb. 2008.
[5] K. Lamkaouchi, Water: a dielectric standard. Permittivity of water-petrol mixtures at microwave frequencies, Ph.D. thesis, Bordeaux I University, France, June 1992, in French.

[6] G.M. Hale and M.R. Querry, "Optical constants of water in the 200-nm to 200- $\mu \mathrm{m}$ wavelength region," Applied Optics, vol. 12, no. 3, pp. 555-563, Mar. 1973.

[7] D. Friedman, "Infrared characteristics of ocean water (1.5-15 $\mu)$," Applied Optics, vol. 8, no. 10, pp. 20732078, Oct. 1969.

[8] L.I. Al'perovich, A.I. Komarova, B.N. Narziev, and V.N. Pushkarev, "Optical constants of petroleum samples in the 0.25-25 $\mu$ range," Journal of Applied Spectroscopy, vol. 28, no. 4, pp. 491-4, Apr. 1978.

[9] V.U. Osadchy, K.S. Shifrin, and I.Y. Gurevich, "The airborne identification of oil films at the caspian sea surface using $\mathrm{CO}_{2}$ lidar," Oceanologica Acta, vol. 22, no. 1, pp. 51-56, 1999.

[10] P.P. Lombardini, B. Fiscella, P. Trivero, C. Cappa, and W.D. Garrett, "Modulation of the spectra of short gravity waves by sea surface films: slick detection and characterization with a microwave probe," Journal of Atmospheric and Oceanic Technology, vol. 6, no. 6, pp. 882-90, Dec. 1989.

[11] T. Elfouhaily, B. Chapron, K. Katsaros, and D. Vandemark, "A unified directional spectrum for long and short wind-driven waves," Journal of Geophysical Research, vol. 102, no. C7, pp. 781-96, 1997.

[12] A.D. Jenkins and S.J. Jacobs, "Wave damping by a thin layer of viscous fluid," Physics of Fluids, vol. 9, no. 5, pp. 1256-64, May 1997.

[13] S.A. Ermakov, "Possibilities of identification of oil films using radar probing of the sea surface," in 2008 IEEE/OES US/EU-Baltic International Symposium (BALTIC), Tallinn, Estonia, May 2008, p. 6 pages.

[14] I. Sergievskaya and S.A. Ermakov, "On wave damping due to oil films," in 2008 IEEE/OES US/EU-Baltic International Symposium (BALTIC), Tallinn, Estonia, May 2008, p. 6 pages.

[15] C. Cox and W.H. Munk, "Measurement of the roughness of the sea surface from photographs of the sun's glitter," Journal of the Optical Society of America, vol. 44, pp. 838-850, 1954. 